\title{
"Overrated Anxiety"___Impact of Corona Virus Disease 2019 Epidemic on Anxiety Levels of Chinese Population
}

\author{
Ting Wang ${ }^{1, \mathrm{a}}$, Yuting Yang ${ }^{1, \mathrm{~b}}$, Linna $\mathrm{Na}^{2, \mathrm{c}^{*}}$ \\ ${ }^{1}$ School of Humanities, Jiangxi University of Traditional Chinese Medicine, Nanchang, China \\ ${ }^{2}$ School of Public Administration, Nanchang University, Nanchang, China
}

\begin{abstract}
Although researches played an important role in the psychological impact of public health emergencies on medical staff and patients' physical and mental health, few previous studies have directly investigated the psychological influence on the Chinese public of Corona Virus Disease 2019 (COVID-19). This study investigated 1503 participants from 29 provinces in China and drew the following conclusions: most (89.4\%) participants were normal, the anxiety levels of women were significantly higher than that of men (p-value: $<0.01$ ), people aged $18-25$ had the highest levels of anxiety of any age group (p-value: $<0.001)$, people who had no contact with heavy epidemic area (Hubei Province in China) were found to have higher anxiety levels than people who contacted with heavy epidemic area (p-value: <0.01). Female, higher educational level and no contact with heavy epidemic area were key risk factors which can predict higher anxiety levels. This study also verified the "psychological typhoon eye effect" and that the quarantine policy was reasonable. These empirical findings in this study could contribute to a better understanding of anxiety impact on the general population and provide empirical support for the mental health intervention work in the epidemic.
\end{abstract}

\section{INTRODUCTION}

After experiencing a series of emergent events of public health, such as the epidemic disease of coronavirus, increasing awareness of the major public health events has been aroused in the decades. As a psychological problem, anxiety has adverse influence on personal body and emotion [2]. According to the previous studies, people who had experienced public health emergencies, such as the severe acute respiratory syndrome (SARS), MERS, Ebola, had commonly suffered different kinds of psychological problems, like post-traumatic stress disorder (PTSD), depression, and especially, anxiety $[1,3,4,5,6,7]$. Through these researches, we can find that the major public health events invariably resulted in the negative effect on the psychology problems, which usually manifest as anxiety. A novel coronavirus (COVID-19) breakout which emerged recently in Wuhan, China was typically an example.

In December 2019, there was an outbreak of pneumonia arising from a novel coronavirus named COVID-19 in Hubei, China. Since 8th, the first coronavirus-infected pneumonia patient showed up in Wuhan, Hubei province, and then the disease spreads quickly. One account of its high contagiousness, rapid change and pathogenicity in the progress of disease and other characteristics, this coronavirus has resulted in an emerging epidemic which can sweep across the country or even the world in a short time. Depression, insomnia, acute stress disorder and anxiety are the common psychological responses. Precious study of anxiety during the early stage of COVID-19 has been restricted to special population especially medical staff and many studies have indicated a high level of anxiety of this group [8, 9, 10, 11, 12, 13].

However, most previous studies have focused on anxiety in specific populations, while ignoring anxiety in the general population. The impact of anxiety levels for the Chinese public remains to be examined. Our study investigated the anxiety status of the Chinese general population in order to provide empirical support for psychological assistance work during the COVID-19 epidemic period.

\section{METHOD}

\subsection{Participants}

To examine the psychological impact of COVID-19, 1503 participants were recruited through a convenience sampling during the COVID-19 period. Of the sample, $41 \%$ came from Hubei, a heavy epidemic area, and the number of confirmed cases in Hubei province as of February 02, 2020 was much higher than that in other provinces. The rest came from other 28 provinces. Additionally, subjects with contact with heavy epidemic area had the proportion of $58.15 \%$. The majority of respondents were female (58.5\%) and under 25 years of age (58.5\%). The sample was dominated by students $(56.8 \%) .68 .60 \%$ of the 
participants had completed secondary or technical secondary school, with only $0.80 \%$ having had a bachelor's degree. All subjects voluntarily and anonymously completed questionnaires. All information collected was kept confidential and used for statistical analysis only.

\subsection{Procedure}

This research was approved by Institutional Review Committee of the Public Administration, Nanchang University. The study was conducted during February 02, 2020 and February 17, 2020 through social software like WeChat and QQ. On a voluntary and anonymous basis, 1503 participants were recruited, completing a questionnaire for about 20 minutes. Through the collation of data, $100 \%$ of the questionnaires were qualified for analysis.

\subsection{Measures}

\subsubsection{Socio-demographic}

Characteristics Questionnaire: The full questionnaire was in Chinese and the study was composed of two parts. The first part concentrated on socio-demographic characteristics of respondents and possible factors associated with anxiety during early stage of COVID-19 in Chinese population. In this research, socio- demographic questions included sex (classified as female and male), age, education (primary school and below, secondary and technical school, university and tertiary, and master degree and above), whether contact with heavy epidemic area.

\subsubsection{Self-Rating Anxiety Scale}

The Scale developed by zung in 1971 called Self- Rating Anxiety Scale is a four-item scale which measures the anxiety of participants. It is extensively used in research, having good psychometric credentials [14]. The SAS is made up of 20 items, and each of them is scored on a 1-4 like scale, from 1 (no or little time) to 4 (most or all time). Higher total score indicates higher degree of anxiety. Different standardized scores (raw data time 1.25) of SAS indicates the different degree of anxiety: below 50 (normal), 50-59 (mild anxiety), 60-69 (moderate anxiety), 70 and above (severe anxiety). In the second part of this questionnaire, our research team used the Chinese version of SAS to examine the anxiety of participants. The Chinese version has been used in the previous studies of Chinese population and its reliability and validity are satisfactory $[15,16]$. The Cronbach's $\alpha$, in this study, for SAS was 0.78 .

\subsection{Data analysis}

Since the number of master degree and above was too small, education level was recategorized into primary school and below, secondary and bachelor degree or above. Age was recategorized into 4 groups (0-18, 18-25, 25-40 and 40-65). Whether contact with heavy epidemic area was redistributed in two: yes and no. Then, we performed a descriptive analysis that expressed the measured sociodemographic characteristics as percentage, mean, standard deviation, standard error of mean and extremum.

Subsequently, surveyors conducted analyses by using SPSS v.20, and completed the following steps: 1) Descriptive statistics were used to summarise the characteristics of the participants. One-way ANOVA and t-test were used to evaluated the SAS scores for different categories variables; 2) The correlation between different categorical variables with the SAS scores was evaluated by Pearson correlation coefficient; 3 )Surveyors used the multiple regression analysis to suggest the relationship between all predictor variables and anxiety.

\section{RESULTS}

\subsection{Summary statistics}

The results showed that $89.4 \%$ participants were normal, $8.9 \%$ were mild anxiety level, $1.3 \%$ were moderate anxiety level and $0.4 \%$ were severe anxiety level. Descriptive statistics analysis has suggested: The study presented the scores of anxiety as a dependent variable $(\mathrm{M}=39.10, \mathrm{SD}=8.22)$. It showed significant differences between groups with different characteristics in the scores of anxiety, including sex $(\mathrm{t}=.23, \mathrm{p}=.002)$, age groups $(\mathrm{F}=5.50, \mathrm{p}=.002)$, contacted with heavy epidemic area $(\mathrm{t}=.12, \mathrm{p}=.002)$, education level $(\mathrm{F}=$ $13.49, \mathrm{p}=.000)$, marital status $(\mathrm{F}=3.11, \mathrm{p}=.045)$, current status $(\mathrm{F}=13.86, \mathrm{p}=.000)$. Those who were female had a higher anxiety level $(\mathrm{t}=.23, \mathrm{p}=.002)$. People who contacted with heavy epidemic area had higher scores of anxiety $(\mathrm{t}=.12, \mathrm{p}=.002)$. A lower education level was associated with a higher anxiety level $(\mathrm{F}=13.49, \mathrm{p}=.000)$. Those who were diagnosed patients or diagnosed patients were nearby had higher anxiety levels $(\mathrm{F}=13.86, \mathrm{p}=.000)$.

Table1.Pearson correlation between anxiety level and COVID19 related factors

\begin{tabular}{|c|c|c|c|c|c|c|}
\hline & & Sex & $\begin{array}{l}\text { Educat } \\
\text { ion } \\
\text { level }\end{array}$ & $\begin{array}{l}\text { Physic } \\
\text { al } \\
\text { condit } \\
\text { ion }\end{array}$ & $\begin{array}{l}\text { Curr } \\
\text { ent } \\
\text { status }\end{array}$ & $\begin{array}{l}\text { Contac } \\
\text { ted } \\
\text { with } \\
\text { heavy } \\
\text { epidem } \\
\text { ic area }\end{array}$ \\
\hline $\begin{array}{l}\text { Scor } \\
\text { es of } \\
\text { anxi } \\
\text { ety }\end{array}$ & $\begin{array}{l}\text { Pearso } \\
\text { n } \\
\text { correlat } \\
\text { ion } \\
\end{array}$ & $\begin{array}{l}.08 \\
* *\end{array}$ & $.12 * * *$ & $\begin{array}{l}-.11 * * \\
*\end{array}$ & $\begin{array}{l}-.14 * \\
* *\end{array}$ & $.08 * *$ \\
\hline
\end{tabular}

0.001 .

\subsection{Correlation between variables}

We performed a Pearson correlation analysis between sociodemographic characteristics and anxiety. As shown in results: (1) the score of anxiety and sex were correlated quite strongly $(\mathrm{r}=.08, \mathrm{p}<.01)$; (2) the score of anxiety correlated with both education level and current status significantly $(\mathrm{r}=.12, \mathrm{r}=-.14, \mathrm{p}<.01) ;(3)$ physical 
condition was negatively linked to the score of anxiety $(\mathrm{r}=$ $-.11, \mathrm{p}<.01) ;(4)$ contacted with heavy epidemic area positively correlated with the score of anxiety significantly $(\mathrm{r}=.08, \mathrm{p}<.01)$. The findings supported for the hypothesized relationships preliminarily.

\subsection{Prediction of anxiety levels}

To determine the quantitative relationship between these variables, the study conducted the multiple regression analyses. Four predictors (education level, social status, contacted with heavy epidemic area and sex) were simultaneously entered into a simple multiple regression model to describe the best predictors of anxiety levels. Then these predictors were entered into the regression equation step by step.

As presented in Table 2: the education level was suggested to influence anxiety state significantly and positively ( $\beta$ coefficients were $0.09, p<.01$ ). Also it found that the physical condition influenced the state of anxiety negatively and significantly $(\beta=-.08, p<.01)$. What's more, contacted with heavy epidemic area was found to predict the state of anxiety significantly and negatively ( $\beta$ coefficients was -0.35 , respectively, $\mathrm{p}<.05$ ). Sex was a significant predictor of anxiety state ( $\beta$ coefficient was 0.06 , $\mathrm{p}<.01$, significantly). Totally, the four predictors explained $20.6 \%$ of variance in the state of anxiety.

Table2.Results of regression analysis for anxiety

\begin{tabular}{|c|c|c|c|c|c|}
\hline $\begin{array}{l}\text { Dependent } \\
\text { variable }\end{array}$ & Predictors & $\mathbf{R 2}$ & B & S.E & $\operatorname{Beta}(\beta)$ \\
\hline \multirow{4}{*}{$\begin{array}{l}\text { Anxiety } \\
\text { level }\end{array}$} & Education level & .03 & 1.44 & .43 & $.09 * *$ \\
\hline & Social status & .05 & -.32 & .13 & $-.07 *$ \\
\hline & $\begin{array}{l}\text { contacted with } \\
\text { heavy epidemic } \\
\text { area }\end{array}$ & .06 & $\overline{5.89}$ & 2.35 & $-.35 *$ \\
\hline & Sex & .06 & .95 & .43 & $.06 *$ \\
\hline
\end{tabular}

Note. ${ }^{*} \mathrm{p}<0.05 ; * * \mathrm{p}<0.01$

\section{DISCUSSION}

This study was the national survey that examined the psychological impact of the COVID-19 epidemic on Chinese public mental health level using Self-Rating Anxiety Scale (SAS). This current study provided empirical data on anxiety in relation to COVID-19 epidemic. Descriptive statistics showed that the anxiety levels of the participants were low (89.4\% participants were normal). The results also indicated that demographic data (sex, age groups, education level) and whether contact with heavy epidemic area were factors related to differences in anxiety levels. In addition, sex, education level and whether contact with heavy epidemic area were factors which can predict anxiety levels.

On the whole, after the occurrence of COVID-19 epidemic, though a small part of the public stilled feel anxious, it appeared that Chinese were inclined to have a more positive state of mind. However, this result was different with the previous study in 2003 severe acute respiratory syndrome (SARS) epidemic [17, 18]. The impact of anxiety led some people to treat 2003 SARS epidemic erroneously [17]. Our results presented here also differed from the earlier finding which showed people who experienced quarantine had bad memories on it [19]. Although most provinces strengthened risk management, people were relatively able to move around freely in 2003 SARS epidemic. Nevertheless, during this COVID-19 outbreak, a more rigorous and comprehensive quarantine was implemented by entire provinces in China. That is suggested that China has taken the bravest, most flexible and active prevention measures to contain the spread of the virus as quickly as possible in the face of this previously unknown virus [20]. Therefore, low anxiety levels were likely to be related to these positive control measures. It can be also explained for the Chinese culture background and Chinese people's trust in these measures.

In this study, the participants' anxiety symptoms were associated with sociodemographic factors of sex, age groups, education level and whether contact with heavy epidemic area. The results suggested that women suffered significantly higher levels of anxiety than male, which supports evidence from the previous clinical observations $[20,21]$. Wang xueyi et al (2003) explained that in the face of major stress events, female's psychological coping capacity is inferior to male's [29]. Besides, anxiety is the most common and serious problem for college students [20]. This may be due to people of 18-25 age group given more pressure from academic achievement and finding jobs.A study from SARS revealed that younger citizens would be more affected by the communication with peers and the dissemination of information on the Internet [22]. In other words, it is also applied on the COVID-19 epidemic. As for educational level, participants with higher education level scored higher in anxiety. This finding was consistent with a previous research [28]. A previous study indicated that education level was an important factor affecting people's cognitive level [29]. People with low levels of education were less knowledge about the epidemic in Chinese population, and those scored lower in anxiety than those with higher levels of education. One interesting finding was that in the "whether contact with heavy epidemic area" group, those who had not been to Hubei Province had higher anxiety levels. Apparently, this study showed results which corroborated the findings of the previous researches in other public emergency events that proved the existence of psychological typhoon eye effect in SARS epidemic and Wenchuan Earthquake [23, 24, 25]. China has experienced a great deal of disasters, but there are few signs of anxiety at the center of the outbreak [24]. Liang Zhe et al first proposed the concept of the "psychological typhoon eye" of risk events [26]. It can be explained the psychological state of the public after the crisis event [27]. Hence, the present study raised the possibility that an accurate portrayal was a typhoon eye of the COVID-19 crisis. In the aspect of predicting factors, female, higher education level and no contact with heavy epidemic area also predicted higher anxiety levels. According to the results, though we need to 
concern mental health of people in Hubei Province, the mentality of people in other provinces need more attention. This is of great importance to the control work of the crisis and the prevention of the rebound in the epidemic. The findings reported here also suggested that psychological workers should pay more attention to these factors which supplied empirical data for psychological intervention in the COVID-19 epidemic.

Finally, a few limitations to this current study need to be acknowledged. First, although several factors were found to predict the anxiety levels significantly, the actual effect of these factors remained to be verified. Second, the weak association of these factors with anxiety levels is interesting, but not surprising. It is possible that the ability to detect significant relationships between variables limited may be due to the small quantity of participants in some predictive factors. Future studies emphasize on establishing a more effective way to prevailing anxiety levels in the COVID-19 epidemic. Indeed, the research would have been more relevant if a wider range of psychological typhoon eye effect had been explored. Further researches, which take these factors into account, will need to be established.

\section{CONCLUSION}

This study adopted the method of empirical research to explore the psychological impact ofCorona Virus Disease 2019 outbreak on anxiety levels of Chinese population. Heavy burden on public health system made by anxiety and depression in some countries [30], and China was no exception. First, the results clearly indicated that most participants $(89.4 \%)$ were normal. A possible explanation for the low anxiety levels of the Chinese public is the reasonable quarantine measures implemented in China. To some extent, China's cultural background and Chinese People's trust in the measures of isolation may also play a positive role to the low anxiety levels of the Chinese public in the COVID-19 epidemic. In addition, Sex, age group, education level and whether contact with heavy epidemic area (Hubei Province) were significantly correlated with anxiety and these variables emerged as predictors of anxiety levels. Future Studies should pay more attention to these risk factors. Finally, the research strengthened the idea that anxiety levels of Chinese public were overrated and provided evidence for the existence of "psychological typhoon effect" in this epidemic. At the same time, it offered a different opinion to regard the anxiety problem in such emergent public health events. These empirical findings in this study could contribute to a better understanding the prevalence and correlates of anxiety during early stage of COVID-19 epidemic in Chinese population, which may provide scientific basis and help to the psychological intervention work. Due to the small sample size and limited persistent period of anxiety in the present study, future investigation is supposed to expand and build upon these results. The methods to establish an effective social psychological crisis intervention system to ensure the mental health of the populations for the country is an important focus for future research.

\section{ACKNOWLEDGMENTS}

This research was financially supported by Jiangxi Social Science Foundation Project of China(20JY20) and Jiangxi Provincial planning of educational science general project of China (19YB015).

\section{REFERENCES}

1. Wu, K. K., Chan, S. K., \& Ma, T. M. (2005).

2. Posttraumatic stress, anxiety, and depression in survivors of severe acute respiratory syndrome (SARS). Journal of traumatic stress, 18(1), 39-42.

3. Spielberger, C. D. (1972). Anxiety: current trends in theory and research: I. Oxford: Academic Press

4. Maunder, R., G, JLancee, W., J, Balderson, K., E, Bennett, J., P, Borgundvaag, B., \& Evans, S. (2006). Long-term psychological and occupational effects of providing hospital healthcare during SARS outbreak. Emerging infectious diseases, 2006, 12(12): 1924., 12(12), 1924-1932.

5. Poon, E., Liu, K. S., Cheong, D. L., Lee, C. K., Yam,

6. L. Y. C., \& Tang, W. N. (2004). Impact of severe acute respiratory syndrome on anxiety levels of front-line health care workers. Hong Kong Medical Journal, 10(5), 325-330

7. Lee-Baggley, D., Delongis, A., \& Voorhoeave, P. (2004). Coping with the threat of severe acute respiratory syndrome: Role of threat appraisals and coping responses in health behaviors. Asian Journal of Social Psychology, 7(1), 9-23.

8. Assiri, A., Al-Tawfiq, J. A., Al-Rabeeah, A. A., AlRabiah, F. A., Al-Hajjar, S., Al-Barrak, A., . . . Memish, Z. A. (2013). Epidemiological, demographic, and clinical characteristics of 47 cases of Middle East respiratory syndrome coronavirus disease from Saudi Arabia: a descriptive study. Lancet Infectious Diseases, 13(9), 752-761.

9. Jalloh, M. F., Li, W., Bunnell, R. E., Ethier, K. A., O'Leary, A., Hageman, K. M., . . . Redd, J. T. (2018). Impact of Ebola experiences and risk perceptions on mental health in Sierra Leone, July 2015. Bmj Global Health, 3(2), e00471.

10. Zhang, W., Li, E., Zheng, L., \& Zhang, Y. (2020). Investigation and countermeasures of anxiety of nurses in a designated hospital of novel coronavirus pneumonia in Hangzhou. Health Research, 40(02), $1-4$.

11. Yang, Y., Zhao, J., Qi, 1., \& Zhang, H. (2020). Anxiety and Social Support of Spouses of First-line Medical Staff in SuiNing City in the Corona Virus Disease 2019 epidemic. CHINESE GENERAL PRACTICE NURSING, 18(08), 940-944.

12. Zhou, X. (2020). Prevention and treatment of anxiety and fear in patients with novel corona virus pneumonia Medical \& Pharmaceutical Journal of Chinese People's Liberation Army, 32(2), 1-3.

13. Zhang, C., Wu, J., Li, J., Guo, X., Liu, S., \& Zeng, 
14. Y. (2020). Analysis on the psychological status of diabetic patients during the epidemic of novel coronavirus pneumonia. Modern Clinical Nursing, 111.

15. Xu, M., \& Zhang, Y. (2020). Psychological status survey of first clinical first-line support nurses flighting against pneumonia caused by a 2019 novel coronavirus infection. CHINESE NURSING RESEARCH, 34(03), 368-370.

16. Cheng, L., Zheng, L., Yan, S., \& Fan, X. (2020). Anxiety status and influencing factors in patients with corona virus disease 2019. Zhejiang Medical Journal, 42(04), 315-317.

17. Tanaka-Matsumi, J., \& Kameoka, V. A. (1986). Reliabilities and concurrent validities of popular selfreport measures of depression, anxiety, and social desirability. Journal of Consulting and Clinical Psychology, 54(3), 328-333.

18. He, J. Q. (2019). Effect of DOL combined with music therapy on labor pain, anxious and depressionof primipara. Chinese Journal of Women and Children Health, 10(4), 70-73.

19. Jiang, X. Y. (2019). Study on the correlation between anxiety and depression level premature infants'mothers and their lactation volume. Chinese Journal of Women and Children Health, 10(3), 16- 19.

20. Einhorn, B. (2003). Where SARS stands on the disaster scale. Online Asia.

21. [18] Tam, K. P., Lau, I. Y. M., \& Chiu, C. (2004).

22. Biases in the perceived prevalence and motives of severe acute respiratory syndrome prevention behaviors among Chinese high school students in Hong Kong. Asian Journal of Social Psychology, 7(1), 67-81.

23. Brooks, S. K., Webster, R. K., Smith, L. E., Woodland, L., Wessely, S., Greenberg, N., \& Rubin, G. J. (2020). The psychological impact of

24. quarantine and how to reduce it: rapid review of the evidence. Lancet (London, England).

25. Huanqiu.com. (2020). Press Conference of WHOChina Joint Mission on COVID-19.[Cite-d 2 Feb 2020.] Available from URL: https://baijiahao.baidu.com/s?id=16595582838560 $57950 \& w f r=$ spider \& for $=$ pc

26. Gao, W., Ping, S., \& Liu, X. (2020). Gender differences in depression, anxiety, and stress among college students: A longitudinal study from China. Journal of Affective Disorders, 263, 292- 300.

27. Seedat, S., Scott, K. M., Angermeyer, M. C., Berglund, P., Bromet, E. J., Brugha, T. S., . . . Kessler, R. C. (2009). Cross-national associations between gender and mental disorders in the world health organization world mental health surveys. . Arch Gen Psychiatry, 66(7), 785-795.

28. Shi, K., Chen, X., Hu, W., Jia, J., Gao, J., Li, D., . . Zhang, L. (2003). Risk cognition characteristics of SARS epidemic in Beijing POPULATION RESEARCH (04), 42-46. 